\title{
Daylight Saving Time and Homicides: Light Effect in Crimes of a Brazilian State
}

\section{Horário de Verão e Homicídios: Efeito da Luz de um Estado Brasileiro}

\author{
Renan Xavier Cortes ${ }^{\mathrm{a}}$ \\ Adelar Fochezatto ${ }^{a}$ \\ Paulo de Andrade Jacinto ${ }^{\mathrm{b}}$
}

\begin{abstract}
This article analyzes the effect of daylight saving time (DST) on crimes in the Brazilian state of Rio Grande do Sul. With the argument that DST provides "more" hours of light throughout the day, it is expected that the criminal behavior will reduce at its implantation, since a clearer environment can dissuade the potential criminal. Making use of several regression discontinuity design (RDD) models and a daily database ranging from 2006 to 2014 of the Mortality Information System (SIM) of Datasus, the models were estimated separately by year, being able to include wheater independent variables (such as temperature, precipitation and wind speed) and fixed effects of days of the week. It was evidenced that DST has no significant effect on changes in homicide rates per 100,000 inhabitants, neither in its beginning, nor its end. On the other hand, it has been found that, in general, there is a strong weekend effect on criminal activity and some evidence that homicide rates are related to temperature.
\end{abstract}

Keywords: Crime. Criminology. Daylight saving time. Homicide rate. Regression discontinuity design.

Resumo: Este artigo analisa o efeito do horário de verão (HV) sobre os crimes no estado do Rio Grande do Sul (BR). Com o argumento de que o HV fornece "mais" horas de luz ao longo do dia, espera-se que o comportamento criminoso diminua na sua implantação, uma vez que um ambiente mais claro pode dissuadir o potencial criminoso. Utilizando diversos modelos de regressão descontinuidade e um banco de dados diário de 2006 a 2014 do Sistema de Informações sobre Mortalidade (SIM) do Datasus, os modelos foram estimados separadamente por ano, podendo incluir variáveis independentes de maior temperatura (como temperatura, precipitação e velocidade do vento) e efeitos fixos de dias da semana. Evidenciou-se que o HV não tem efeito significativo na mudança das taxas de homicídio por 100.000 habitantes, nem em seu início, nem em seu fim. Por outro lado, verificou-se que, em geral, há um forte efeito de fim de semana sobre a atividade criminosa e algumas evidências de que as taxas de homicídio estão relacionadas à temperatura.

a Pontifícia Universidade Católica do Rio Grande do Sul (PUCRS), Escola de Negócios, Programa de Pós-Graduação em Economia (PPGE). Porto Alegre, Rio Grande do Sul, Brasil.

b Universidade Federal do Paraná, Departamento de Economia (DEPECON). Curitiba, Paraná, Brasil. 
Palavras-chave: Crime. Criminologia. Horário de verão. Taxa de homicídios. Regressão com descontinuidade.

JEL Classification: C14; Q58; K42.

\section{Introduction}

According to the rational choice theory of delinquent behavior from Becker (1968), the individual chooses to commit a crime if the expected benefits are greater than the expected costs where several factors influence both incentives. Regarding the expected benefits, criminals can assess the financial return of crime and/ or the psychic return of crime by increasing their utility. On the other hand, costs considered are planning time, probability of being captured, severity of punishment, moral cost, labor instrument cost (such as a firearm), opportunity cost in the legal labor market, etc. In this context, the probability of being captured may play an important deterrent to crime.

According to Doleac and Sanders (2005), an environment of greater clarity makes the witnesses more apt to see offenders committing crimes. In other words, this environment facilitates the identification of criminals by individuals, increasing the number of potential witnesses and identification of perpetrators in case of seizure. In their model, the expected cost of crime is a function that depends, besides other factors, on the probability of capture, which depends on the light of the environment. Among some papers that relate the clarity of the environment to criminal activity, we can highlight Salvi (2011), which studied the additional perpetuation of lights in Los Angeles, and Arvate et al. (2015), who evaluated the Brazilian federal program Luz para Todos (Light for All) in the rural environment, which found a reduction in the number of violent crimes.

One of the ways to assess whether clarity affects criminal behavior is to make use of daylight saving time (DST). DST consists in advancing the clock one hour during the months close to summer, making daylight better utilized in the beginning of the night and, consequently, causing "more" hours of sunlight during the afternoon. In this sense, society would save energy, with this being its main objective (ARIES; GUY, 2008). Although time of day plays a very important role in social organizations, affecting the moment of waking up, working, lunch, sleeping, etc., this article justifies its approach under the hypothesis that there is a criminal deterrence effect through brightness of the environment.

Several papers analyze the effect of DST with different objectives. Kountouris and Remondou (2014) find evidence for Germany that DST has a negative influence on satisfaction and mood, especially on people who work full time. Smith 
(2016) examines the effect of DST in fatal car accidents pointing that it increases the risks due to the change in the sleep schedule and the reallocation of morning light to evening. Toro et al. (2015) also show that the shift to DST has an influence on the risk of acute myocardial infarction. Kotchen and Grant (2011) find evidence contrary to the main objective of DST, as their results indicate that there is an approximately $1 \%$ increase in energy consumption for the state of Indiana in the USA. In addition, Kellogg and Wolff (2008) have no effect on energy consumption in Australia. In beneficial terms, Wolff and Makino (2012) show that the time spent in recreation increases during DST, while the time spent at home watching television decreases and this translates into an additional 10\% calorie burn.

In terms of criminality, Doleac and Sanders (2005), making use of regression discontinuity design (RDD) and differences-in-differences, evaluate the effects of change on DST in United States (US) in various crime categories. They estimate a 7\% drop in robberies after the DST beginning and a $11 \%$ reduction in rapes, in addition, they estimate a significant social cost savings through the simple extension of DST policy in US.

In Brazil, Toro et al. (2016) analyze the effect of DST in Brazilian states for firearm deaths, since this type of murder plays an important role in Brazilian crimes (DE SOUZA et al., 2007). Considering that in Brazil some states adopt the DST policy and others do not, ${ }^{1}$ their work, making use of RDDs, difference-in-difference and differences in discontinuities, analyzed within and between state effects, comparing "treated" and "untreated" states. In addition, Toro et al. (2016) estimated that the change in ambient light caused by the DST was responsible for saving about 3,850 potential victims from 2006 to 2011.

Based on these considerations, this article aims to analyze the effect of the change in DST in homicide cases for the Brazilian state of Rio Grande do Sul (RS) between the years 2006 and 2014. The study differs in some respects in relation to Toro et al. (2016). The first, the specific case of a UF, RS, will be evaluated, allowing a more detailed analysis from the intra-annual point of view, with the inclusion of climatological covariates such as temperature, precipitation and wind speed. This is an important contribution insofar as in the state of RS, climate changes are well defined. In addition, there is abundant evidence of the association between climatic variables and the occurrence of crimes reported in the literature, such as the studies of Ceccato (2005) for Brazil, Michel et al. (2016) and Ranson (2014) for the United States, Horrocks and Menclova (2011) for New Zealand and Tompson and Bowers (2015) for Scotland. The second, it will also be of interest to evaluate the effect of the exit of the DST, since this type of intervention is characterized by the reduction of hours of

1 The states that adopts the DST are Rio Grande do Sul, Santa Catarina, Paraná, São Paulo, Rio de Janeiro, Espírito Santo, Minas Gerais, Bahia (in 2011), Goiás, Mato Grosso, Mato Grosso do Sul and Distrito Federal. 
sunshine throughout the afternoon. That is, if the number of homicides is expected to decrease when DST is started, it is reasonable to assume that it will rise as DST ends, something unheard of in the literature related to the subject.

The article is structured in five sections besides this introduction. In Section 2 it is presented a review of the Brazilian Energy Policy. Section 3 describes the source of the data and the empirical strategy. The results are presented and discussed in Section 4. Section 5 describes the robustness tests. Section 6 presents the final considerations. The results show that DST has no significant effect on changes in homicide rates per 100,000 inhabitants, neither in its beginning, nor its end. However, we found that there is a strong weekend effect on criminal activity and some evidence that homicide rates are related to temperature.

\section{Brazilian Energy Policy}

The DST is a policy that aims to reduce electricity consumption in the evening, between $6 \mathrm{pm}$ and $9 \mathrm{pm}$, by making better use of natural light. It was first adopted in Brazil in 1931, but it was only from 2008 that it became regulated its obligatoriness. The decree that regulates it establishes the regions in which it takes effect, the moment it starts each year (midnight on the third Sunday of October) and the moment it ends (midnight on the third Sunday of the month of February of the following year). Since then the program has been adopted normally.

In 2017, a study carried out by the National Electric System Operator and the Ministry of Mines and Energy pointed out that between 2013 and 2016 the energy saved decreased from $R \$ 405$ million to $R \$ 159.5$ million per season. The study says that because of changes in consumer habits, the program no longer has the same effect in past years in terms of reducing energy consumption at peak times, leading to a reduction in energy savings. The justification is that there was a shift in the schedule of higher consumption of electricity, which used to be in the interval between $17 \mathrm{~h}$ and $20 \mathrm{~h}$ and is currently in the interval between $14 \mathrm{~h}$ and $15 \mathrm{~h}$. Due to this study, in 2017 the government considered ending the program, which did not happen. The debate is set and goes beyond the technical question of energy saving, because interested parties, such as producers of drinks, bars and restaurants, have already expressed their support for the maintenance of the program. This study, when testing the hypothesis that DST affects crime, is also inserted indirectly in this debate. 


\section{Methodology}

In this section, we detail the data, methodology and design approach used of this study. We will give a general overview of the data and the mathematical background for the regression used.

\subsection{Data Source}

The Brazilian Ministry of Health through the Mortality Information System (SIM) has mortality information at the municipal level, including date and time of death. The SIM is a reliable source of data since it relies on legal certificates of mortality regulated by the federal government. In this database it is possible to identify the cause of death through the codes of the International Statistical Classification of Diseases and Related Health Problems (ICD-10). Another database to be used is one of the National Institute of Meteorology (INMET) which has daily public weather data for 19 municipalities in Rio Grande do Sul where meteorological stations are installed. The municipal population data were obtained from the estimates of the Statistics and Economics Foundation of Rio Grande do Sul (FEE-RS).

In the field of criminality, due to the reliability level of homicide information, this is often used to estimate the crime rate of a given region. The homicides committed with firearms, including also, the homicides caused by sharp, penetrating and blunt objects will be used. In addition, the occurrence of crimes for undetermined intent. Table 1 describes the ICD-10 categories used in this work.

Table 1 - Code description of ICD-10 used

\begin{tabular}{ll}
\hline Code & Description \\
\hline X93 & Assault by handgun discharge \\
X94 & Assault by rifle, shotgun and larger firearm discharge \\
X95 & Assault by other and unspecified firearm discharge \\
X99 & Assault by sharp object \\
Y00 & Assault by blunt object \\
Y22 & Handgun discharge, undetermined intent \\
Y23 & Rifle, shotgun and larger firearm discharge, undetermined intent \\
Y24 & Other and unspecified firearm discharge, undetermined intent \\
\hline
\end{tabular}

Source: Elaborated by the author.

An important feature, which is also raised in the work of Toro et al. (2016), is the relation if the increase in mortality during the hours most affected by the DST are results of a crime-lagging effect occurring in hours before DST. For example, it may happen that a victim who has suffered a criminal incident (a shot, for exam- 
ple) hours before sunset ends up dying in the hospital hours near the DST transition time. One possible way to try to circumvent this spurious effect is to limit the study to cases where the victim died at the scene of the crime. ${ }^{2}$ In this sense, the analyzes contemplate this characteristic working only with the cases that occurred outside hospitals or other health establishments. ${ }^{3}$

\subsection{Regression Discontinuity Design}

The RDD or discontinuous regression method can be used when the probability of receiving a treatment changes discontinuously with a numerical variable. The idea of this method is to evaluate the effect of an intervention in the surroundings of values "closer" of what was defined as intervention threshold. It is expected that if there is an effect on the intervention, there will be a discontinuity in these more critical values since the observational units that will be closer to this threshold will have greater incentives (or not) to change the values of the dependent variable. With this expected hypothesis, this jump due to the change in status of receiving treatment can be interpreted as a local average treatment effect. Thus, this is one of the points that may represent a limitation of the method, since it estimates an average effect of the treatment comparing only individuals around this cut-off point and, therefore, extrapolations to the rest of the population should be made with caution.

According to Menezes Filho et al. (2012), one of the first works to introduce the idea of regression discontinuity was Thistlewaite and Campbell (1960) in which this method was used to evaluate the impact of a merit award on students' academic performance. Another application, still in the education economics, can be seen in Dee and Wyckoff (2013) which used RDD to evaluate performance and probability of retention of teachers in an evaluation system that had financial incentives for those with scores above a certain value and threat of dismissal for teachers with performances below a certain score. In this sense, this study used this method for two discontinuities: between teachers with threat of dismissal and average teachers and another discontinuity between average teachers and teachers who received financial incentives.

Specifically, in the case of using the method to evaluate the effect of DST, the variable that undergoes the intervention is the time measured by the days after the

2 In SIM database, there is a variable of Death Occurrence Location in which it is possible to filter by hospital, public road, home, etc.

3 Two important features must be raised in this regard: the first is that this type of filter is more conservative because observations are missed where the victim is injured and is quickly admitted to a hospital and dies soon after their admission and, secondly, also excludes those cases in which the execution took place inside a hospital. This filter resulted in a reduction of $27.54 \%$ of cases, but our model proved to be robust regarding this data treatment, as presented in Section 5.5. 
establishment of the DST. With this, the variable takes negative discrete values before the intervention and discrete positive values after the intervention, assuming the value zero on the first day after the DST. This type of discontinuous regression is called the "sharp" type, since the regions have zero probability of participating in the DST in the days preceding it, but they have probability equal to one after the intervention.

In order to define the local average treatment effect (LATE), we define a variable of interest $Y$, which in our case are the criminal events, a variable $Z$, which are the number of days after the DST, and a constant $c$ that determines when the observational unit will be treated. As defined, in our case this constant will be zero because it represents exactly the first day after the establishment of the DST. The LATE is defined as:

$$
D(c)=E\left[Y_{(1)} \mid-=c\right]-E\left[Y_{(0)} \mid Z=c\right]
$$

However, it is not possible to observe ${ }_{(1)}$ and ${ }_{(0)}$ for the same region, what is observed in fact is:

$$
Y=Y_{(0)}-\left(Y_{(1)}-Y_{(0)}\right) \times T
$$

where $T=1=>Y=Y_{(1)}$ and $T=0=>Y=Y_{(0)}$. However, a treatment variable $T$ depends on a continuous covariable $Z$ which undergoes a discontinuity. Therefore, the expected value for treated unities (after threshold) is given by:

$$
E[Y \mid Z=c+\varepsilon]=E\left[Y_{(0)} \mid Z=c+\varepsilon\right]+E-\left[\left(Y_{(1)}-Y_{(0)}\right) \times T \mid Z=c+\varepsilon\right]
$$

and for individuals below the threshold (before DST) is given by:

$$
E[Y-Z=c-\varepsilon]=E\left[Y_{(0)}-Z=c-\varepsilon\right]+E-\left[\left(Y_{(1)}-Y_{(0)}\right) \times T-Z=c-\varepsilon\right]
$$

In the sharp case, the switch to treatment is abrupt, where all the observational units with a value of $Z$ above the constant $c$ receive the treatment and all the others do not receive. The LATE is:

$$
\begin{gathered}
D(c)=Y^{+}-Y^{-}=\lim _{\varepsilon \downarrow 0} E[Y \mid Z=-+\varepsilon]- \\
\varepsilon \downarrow 0
\end{gathered}
$$

For illustrative purposes, Figure 1 shows this sudden change in treatment probability shortly after DST change. 
Figure 1 - Representation of a sharp intervention

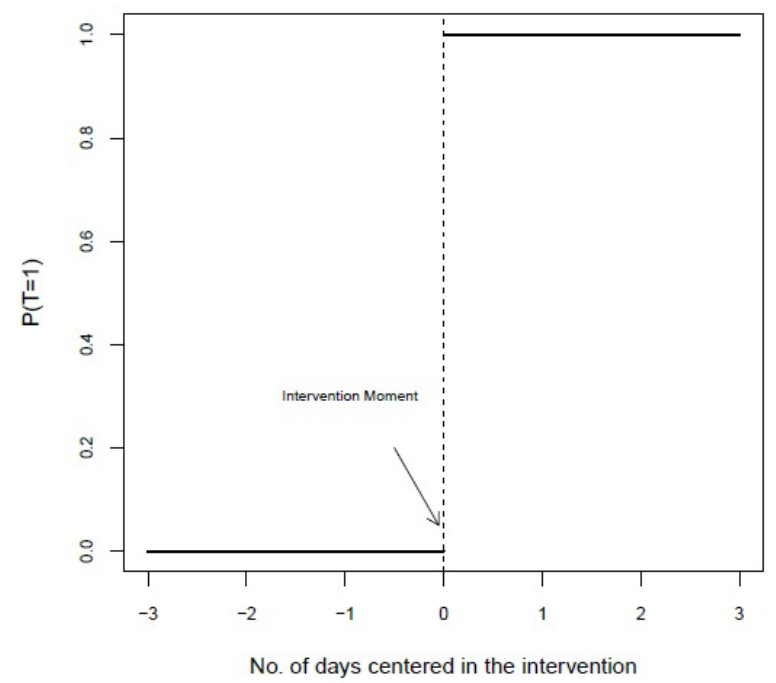

Source: Elaborated by the author.

In terms of modeling, the equation below presents the model in its reduced form:

$$
Y_{d a}=\beta_{0}+\tau I\left(T_{d a} \geq 0\right)+g\left(T_{d a}\right)+X_{d a} \beta+\varepsilon_{d a}
$$

where $d$ represents the number of days after DST, $a$ represent years, $T_{d a}$ is the horizontal axis variable (also referred as running variable), $X_{d a}$ represents a vector of covariates, $g($.$) is a flexible function nonparametrically estimated, Y_{d a}$ is the dependent variable which, in this case, is the homicide rate per 100,000 inhabitants and $\tau$ represents the effect of DST discontinuity on the dependent variable and can be interpreted as the local effect of the treatment. As in Doleac and Sanders (2005) and Toro et al. (2016), it is expected that the criminal rate falls more sharply in the hours most affected by the transition. Thus, models will be estimated by analyzing both the full day and the hours close to sunset (both before and after). Additionally, covariables will be included as the day of the week and climatological variables.

This type of discontinuity regression can be seen as a semiparametric model, being a particular case of the Generalized Additive Models (GAM) (LOEFFLER; GRUNWALD, 2015). Thus, its equation will be estimated via GAM, where its nonparametric function of the $T$ variable will be estimated via local linear polynomial regression Loess (CLEVELAND; DEVLIN, 1988) with smoothing parameter equal to 0.5 . 


\subsection{Data Preparation}

Before presenting the results obtained, some considerations must be made regarding the data used in the study. Firstly, to control the possible idiosyncrasies of the data it is emphasized that models will be estimated with the inclusion of covariables, such as weekdays and daily climatological variables. In addition, this paper uses homicide rates as dependent variable, that is, it is already corrected by the size of the population. The climatological variables obtained on the INMET website are average temperature information, ${ }^{4}$ wind speed and pluviometric precipitation. ${ }^{5}$ Considering that INMET presents data only for 19 municipalities where meteorological stations are present, the estimated values for RS represent a weighted average by the population of each of these municipalities.

Another important fact that is taken into account is that on the day that the DST begins, clocks must be advanced by one hour and in this sense the day "loses" one hour which could underestimate the number of homicide cases on the day immediately following the change in DST. To correct this possible distortion, the number of homicides occurring on this day is multiplied by $24 / 23 .{ }^{6}$ Similarly, when DST is terminated the number of deaths of the immediately subsequent day is multiplied by 23/24.

The variable that represents the number of days until the start (or end) of DST is constructed according to Table 2 .

Table 2 - DST dates implemented

\begin{tabular}{|c|c|}
\hline Season & Duration \\
\hline $2005 / 2006$ & from 0am of October 16, 2005, until 0am of February 19, 2006 \\
\hline $2006 / 2007$ & from 0am of November 5, 2006, until 0am of February 25, 2007 \\
\hline $2007 / 2008$ & from 0am of October 14, 2007, until 0am of February 17, 2008 \\
\hline $2008 / 2009$ & from 0am of October 19, 2008, until 0am of February 15, 2009 \\
\hline $2009 / 2010$ & from 0am of October 18, 2009, until 0am of February 21, 2010 \\
\hline 2010/2011 & from 0am of October 17, 2010, until 0am of February 20, 2011 \\
\hline $2011 / 2012$ & from 0am of October 16, 2011, until 0am of February 26, 2012 \\
\hline $2012 / 2013$ & from Oam of October 21, 2012, until 0am of February 17, 2013 \\
\hline $2013 / 2014$ & from Oam of October 20, 2013, until 0am of February 16, 2014 \\
\hline $2014 / 2015$ & from Oam of October 19, 2014, until 0am of February 22, 2015 \\
\hline $2015 / 2016$ & from Oam of October 18, 2015, until 0am of February 21, 2016 \\
\hline
\end{tabular}

Source: Elaborated by the author.

4 In the meteorological stations three temperature readings are made every six hours. For a perfect control, a fourth reading should be done, which is not usually the case. Thus, the average temperature that is calculated is not exactly the average of the day. What meteorologists do then is to calculate an average of the three readings, plus the maximum and the minimum. The average of these five values is called average temperature compensated and this is the information used here.

$5 \quad$ Other variables were considered but excluded due to excess of missing data.

6 This correction is also made by Toro et al. (2016) although the results have been robust to it in their work. 


\section{Results}

In this section, we present the main descriptive results, as well as the main results of the analysis. We highlight that we investigated the start and the end of DST.

\subsection{Descriptive Statistics}

In this section we analyze some descriptive statistics of the SIM database for Rio Grande do Sul in the period between 2006 and 2014. Figure 2 shows daily homicide rates per 100 thousand inhabitants stratified per year. We see that the values oscillate near 0.04 with some outliers surpassing the values of 0.12 . In addition, there is no specific year that distinguishes itself from others in level terms. On the horizontal axis of each these graphs are the number of days in relation to the start day of DST (negative values for previous days and positive for later ones) and the dashed vertical line located at zero represents the first day of DST.

A pre-regression nonparametric line was included in each of the charts to check the trend of criminal rates. If there is a structural change between the period before and after the dashed lines, the nonparametric trend is expected to undergo a change as it traverses them, something that is not apparent when we analyze these raw data graphs. However, possible structural breaks may be present in the separate estimates between the two period segments (pre and post intervention).

Figure 2 - Homicide rates stratified per year in Rio Grande do Sul

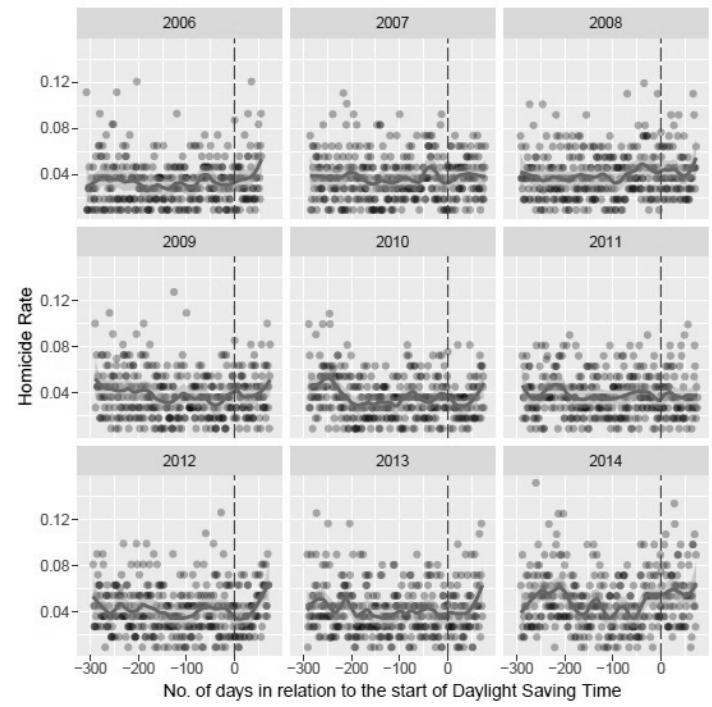

Source: SIM ([2018]); FEE ([2018]). 
When we do not distinguish per year from the series and analyze only the 80 days next to the entry of the DST (40 days before and 40 days later) the resulting graph is that represented in Figure 3. This graph illustrates the overall behavior of $\mathrm{RS}$ crime rates in the days close to the entry of DST without distinction of year, i.e., making the overall RS rate grouped by days. This visualization again does not make it clear if there is a structural break close to the zero day line.

Figure 3 - General homicide rates in Rio Grande do Sul only in a period close to the entry of DST

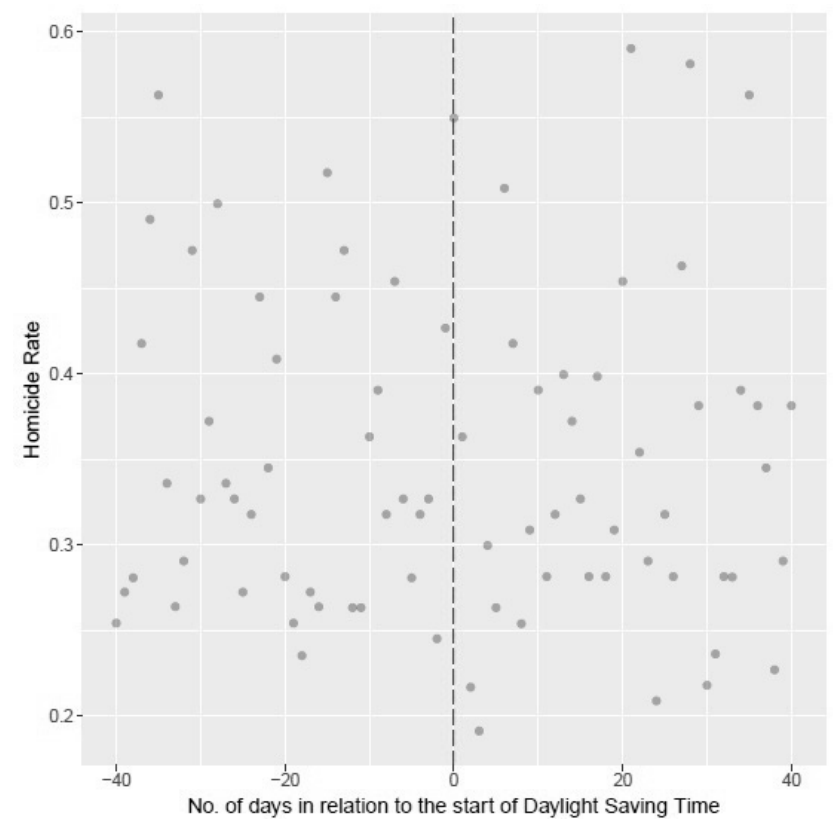

Source: SIM ([2018]); FEE ([2018]).

An interesting aspect is to analyze the temporal location of homicide occurrences. More specifically, see where the highest and lowest homicide rates occur in terms of months of the year, days of the week and times throughout the day. Regarding the months of the year, we notice that the hottest months of the year like December, January, February and March have significantly higher rates than the mid-year months. This pattern has been observed in numerous studies such as Ceccato (2005) for Brazil, Ceccato and Uittenbogaard (2011) and Ceccato and Uittenbogaard (2014) for Sweden, Andresen and Malleson (2015) for Canada, Field (1992) and Farrell and Pease (1994) for England, Cohn and Rotton (2000) and Rotton and Cohn (2003) for the United States and Landau and Fridman (1993) for Israel where the analysis is restricted to the seasonal pattern. 
In the descriptive analysis of the days of the week, it was observed that there is, significantly, ${ }^{7}$ a greater concentration of homicides on weekends (Saturday and Sunday), while the days that showed a lower degree of occurrence are midweek days such as Tuesday or Wednesday. The distribution of homicides on weekdays is well defined having high values on weekends followed by a gradual reduction to mid-week and then a gradual rise to arrive at the weekend again. Therefore, there is a "day-of-the-week" effect that must be included in the analysis.

This result can be observed in Andresen (2014) who describes the importance of criminological day in which the temporally referenced crime data is organized along a timeline having the days of the week as reference. Although we do not find a formal theory that describes the reasons for the greater occurrence of crimes at the end of the week, there are countless studies that show the highest occurrence of the crimes at the weekend such as Ceccato (2005), Ceccato and Uittenbogaard (2014), Andresen and Malleson (2015), Michel et al. (2016), Newton and Hirschfield (2009), suggesting the existence of a possible weekend effect. The mechanism of transmission is not clear, but according to these studies, this effect would be related to the increase of agglomerations and the use of alcohol at the weekends.

Regarding the death schedules, the distribution is quite interesting and Figure 4.3 shows the frequency of homicides that were recorded for every minute of the day of the entire study sample. ${ }^{8}$ In this frequency chart, it is highlighted with labels the times that presented values above 50 and it is possible to analyze that, except for the time of the first ten minutes of the morning, they are all well-defined hours of the day, that is, are either complete hours or half an hour. With regard to the complete hours, stand out night schedules like 1am, 7pm, 8pm, 9pm, 10pm and $11 \mathrm{pm}$. This type of behavior is in line with what was discussed in Section 1, where an environment with poor clarity leads to delinquent behavior. This graph, therefore, corroborates the motivation of this paper.

In general, it is possible to note that the overall distribution tendency of homicide cases follows a smooth curve having a "valley" at hours close to noon and having two "hills". The first "hill" is represented by the hours of dawn having a peak in 1am, while the second "hill" is located in the hours of the end of the day having its peak at 22pm.

The complete hours have a high frequency and prominence in the graph. However, it is also possible to observe that, interspersed with complete hours, there are intermediate times appearing every half hour with a frequency pattern similar to full hours, where their highest values are at 8:30 p.m., 9:30 p.m., 10:30 p.m.

7 Kruskal-Wallis nonparametric tests were performed with Dunn's multiple comparisons with $\alpha=5 \%$ to compare months of the year and days of the week. This test is analogous to Analysis of Variance (ANOVA) and was used because the residuals did not adhere to the normality hypothesis.

Part of the sample (almost 0.3\%) was considered missing, since the death time field was not filled. In addition, we did not consider the deaths that presented the 00:00 time, placing them as missing as well. 
and 11:30 p.m. This location pattern of most criminal occurrence draws attention to the fact that there might be a possible imprecision and knowledge of the exact time the murder occurred. It is reasonable to assume that the real distribution is somewhat smoother between minutes, but because of the ease and convenience of recording, more defined times are chosen for specific hours or half an hour between these times. Despite these caveats with respect to the data it is possible to visualize more "broken" times illustrated in small bars along the graph of Figure 4.

Figure 4 - Homicide rates by time of occurrence in Rio Grande do Sul

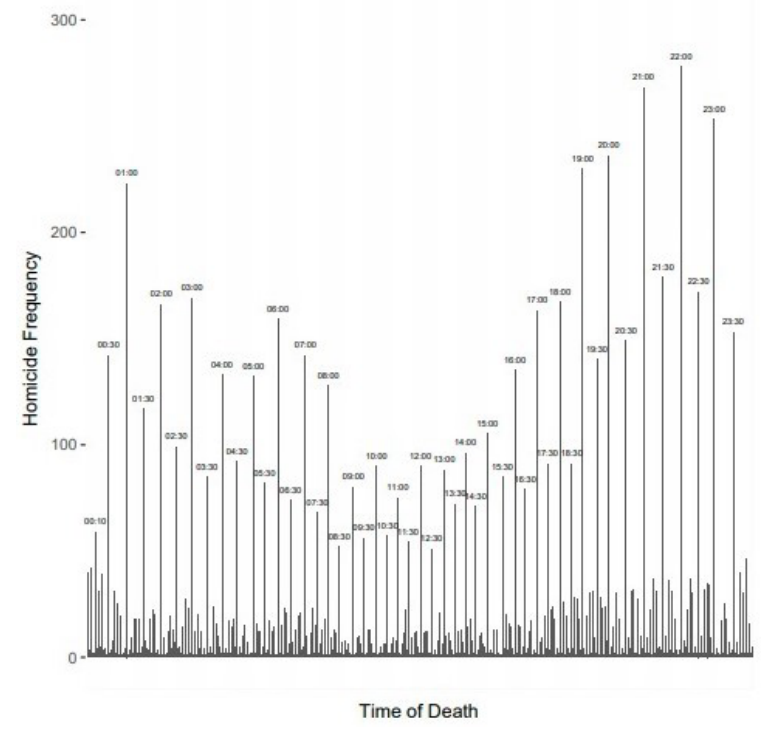

Source: SIM ([2018]); FEE ([2018]).

Through the INMET data it is possible to analyze if there is some kind of relation between criminal rates and climatic variables. The main variable that proved to be important in the homicidal relationship was the average temperature of the days. There is a trend that on warmer days, homicidal rates are higher. Most linear correlations were positive and significant ( $\alpha=5 \%$ ).

The relation of temperature to criminal behavior has already been discussed in some studies in the literature. Ranson (2014) shows that, for US, there is a strong positive effect between monthly temperature and murder, rape, theft, vehicle theft, among others. Gamble and Hess (2012) verify that, for Dallas, the daily temperature had a strong relation with severe aggressions, being characterized by an inverted $\mathrm{U}$ with inflection point at 32.2C. In addition, the authors found a similar relationship for sexual assaults and homicides, but not very explanatory. Britto (2014) analyzes criminal data from Juiz de Fora (Brazilian state of Minas Gerais) 
and several climatic variables, where the monthly temperature is related to death by homicide. For Pelotas (Brazilian city of Rio Grande do Sul state), Silveira and Vieira (2001) analyze graphically the positive relation between the increase of the monthly temperature and the increase of the homicides.

\subsection{Regression Discontinuity: Start of DST}

In this section we present the main results of the estimated RDDs for the DST entry period. The main models follow the structure similar to that described in Section 3.2, being represented by two equations: one adding covariates and other not. Equation 7 represents the complete model:

$$
H R_{d a}=\beta_{0}+\tau I\left(T_{d a} \geq 0\right)+g\left(T_{d a}\right)+\beta_{1} T e \mathrm{Tp}_{d a}+\beta_{2} \operatorname{Prec}_{d a}+\beta_{3} W \mathrm{ind}_{d a}+\beta_{\mathrm{k}} D a \mathrm{y}_{d a}+\varepsilon_{d \mathrm{a}}
$$

Where $k=$ monday, tuesday, ..., saturday the index of the day-of-week fixed effect (sunday is the reference category), $d$ o index of the day and $a$ the year index, where each equation is estimated for each year separately. The dependent variable is $H R$ (homicide rate) and the covariates are abbreviated as Temp (temperature), Prec (pluviometric precipitation) and $W$ ind (wind speed). In addition, we estimate a model without covariates, according to Equation 8:

$$
H R d a=\beta 0+\tau(T d a \geq 0)+(T d a)+\varepsilon d a .
$$

Regarding DST entry, the main results are summarized in Table 3 and Figure 5.9 In all years and models it was observed a high absence of significance with the exception for the model with no covariates in 2007 that showed some level of significance below $\alpha=0.05$. The results of the discontinuity effect indicate that, for DST entry, there is neither increase nor drop in homicide rates indicating that, if any, it is due only to random fluctuations of the data. Only in 2007, there is an indication of the positive effect of DST on criminal rates of $\tau=0.0195$, i.e., with an opposite direction than expected.

Figure 5 illustrates the main results of the nonparametric regressions between the period prior to the implementation of the DST (Pre-Period) and the later period (Post-Period) for the models without covariates. It is possible to verify that the local regression curves do not, in fact, show any signs of abrupt changes of direction when it crosses $T=0$. In addition, the $95 \%$ confidence intervals between pre- and post-discontinuity period have a large intersection in values. In this figure, however, we can note the result consistent with the only significance found in the

9 It makes sense to take a look, previously, at the effect of possible discontinuity on covariates to justify their use in increasing the precision of $\tau$. According to them, we can see that there is little (or no) significant discontinuity effect of the DST entry in climate variables, except for a drop in temperature in 2006 (Sig. $\approx 0.0266$ ), an increase in precipitation in 2006 (Sig. $\approx 0.0243$ ), a fall in precipitation in 2014 (Sig. $\approx 0.0259$ ) and an increase in wind speed in 2013 (Sig. <0.0001). 
previous Table 3 for the year 2007. In the central upper chart, the nonparametric trend of the post intervention period goes up when $T=0$ indicating an increase in the homicide rate soon after DST entry.

Table 3 - Local effects of DST entry for all years and models

\begin{tabular}{cccc}
\hline Year & Effects $(\tau)$ & Significance & Does it include covariates? \\
\hline 2006 & 0.0116 & 0.1431 & Yes \\
2006 & 0.0134 & 0.1807 & No \\
2007 & 0.0175 & 0.0600 & Yes \\
2007 & 0.0195 & 0.0300 & Yes \\
2008 & 0.0046 & 0.6345 & No \\
2008 & 0.0060 & 0.5807 & Yes \\
2009 & -0.0043 & 0.6054 & No \\
2009 & -0.0034 & 0.6827 & Yes \\
2010 & -0.0077 & 0.3085 & No \\
2010 & -0.0029 & 0.6966 & Yes \\
2011 & 0.0000 & 0.9991 & No \\
2011 & 0.0012 & 0.8814 & Yes \\
2012 & -0.0084 & 0.3536 & No \\
2012 & -0.0090 & 0.3524 & Yes \\
2013 & -0.0010 & 0.9171 & No \\
2013 & -0.0004 & 0.9638 & Yes \\
2014 & 0.0041 & 0.6898 & No \\
2014 & 0.0095 & 0.4035 &
\end{tabular}

Source: Elaborated by the author.

Figure 5 - Regression discontinuity at the entrance of DST in models without covariables.

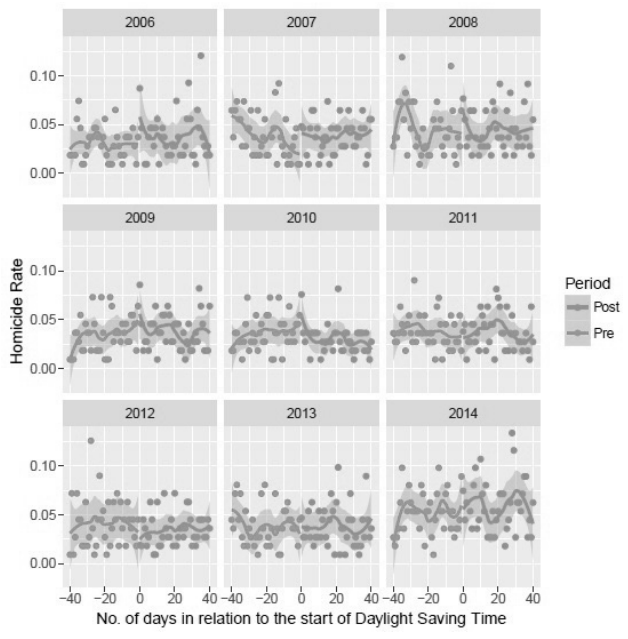

Source: Elaborated by the author; SIM ([2018]); FEE ([2018]). 
Another interesting result to analyze is the relation of the climatic covariates in the regressions of the Model 1. We assess the effect of all the years of temperature, precipitation and wind speed. Again, most of the effects are null, except for the average temperature that, in 2006, 2013 and 2014, was positively related to homicide rates. In addition, in 2008, there was an inverse effect between wind speed and rate, indicating that this year, as there was more wind in RS, there were fewer homicides (Sig. $=0.0408$ ).

The weekday covariates were the ones that presented the most relevant in the model as previously discussed. The weekday effect is negative and significant in most of the betas, indicating a Sunday homicide.

A very important feature of the intervention, which cannot be ignored, is that both the start and the end of DST, always occur at dawn between Saturday and Sunday. Moreover, we found that the day of the week has a considerable influence on criminal practice both in descriptive terms, as seen in Section 4.1, and in inferential terms as now analyzed in the effect of its covariate. However, the effect of Saturday in relation to Sunday (illustrated by the coefficient of Saturday) is not so strong and, for the most part, it is not significant what indicates that there is a "weekend effect" in criminal activity. That is, there is a historical "weekend" discontinuity while DST will necessarily be confused with the "Saturday vs. Sunday" effect. Since the effect of the discontinuity of the regression is local and takes into account the neighborhood of the points the effect, "Friday vs. Saturday" locally affects the transition "Saturday vs. Sunday".

\subsection{Regression Discontinuity: End of DST}

In this section we present the results of DST ending. ${ }^{10}$ Table 4 and Figure 6 illustrate the main results of this approach.

Table 4 - Local effects of DST ending for all years and models

\begin{tabular}{lccc}
\hline Year & Effects $(\tau)$ & Significance & Does it include covariates? \\
2006 & -0.0039 & 0.6746 & Yes \\
2006 & 0.0051 & 0.6176 & No \\
2007 & 0.0129 & 0.1983 & Yes \\
2007 & 0.0096 & 0.3610 & No \\
2008 & -0.0132 & 0.1825 & Yes \\
\hline
\end{tabular}

Continua...

10 Previously, it makes sense to analyze the discontinuity effect on covariates. In most of the models, there was no significance, but in other years these discontinuities deserve attention. In relation to temperature, we can see that in general there is a decreasing trend of temperature as leaving the summer. However, we see positive discontinuities with effect of 2.59 in 2007 (Sig. $=0.0033$ ) and 1.54 in 2009 (Sig. = 0.0292). Regarding precipitation, we noticed a discontinuity of 5.42 in 2006 (Sig. = 0.0254) and -11.64 in 2007 (Sig. < 0,001). The wind speed presented discontinuity in 2006 $(0,53$ with Sig. $=0.0375), 2009(-0,499$ with Sig. $=0.0355)$ and $2013(0,7565$ with Sig. $=0.0154)$. 
Conclusão.

\begin{tabular}{lccc}
\hline Year & Effects $(\tau)$ & Significance & Does it include covariates? \\
2008 & -0.0070 & 0.4690 & No \\
2009 & -0.0143 & 0.0880 & Yes \\
2009 & -0.0088 & 0.3622 & No \\
2010 & -0.0130 & 0.2104 & Yes \\
2010 & -0.0125 & 0.1933 & No \\
2011 & 0.0058 & 0.4814 & Yes \\
2011 & 0.0077 & 0.3804 & No \\
2012 & 0.0073 & 0.3544 & Yes \\
2012 & 0.0091 & 0.3198 & No \\
2013 & -0.0374 & 0.0002 & Yes \\
2013 & -0.0346 & 0.0007 & No \\
2014 & 0.0092 & 0.4569 & Yes \\
2014 & 0.0057 & 0.6194 & No \\
\hline
\end{tabular}

Source: Elaborated by the author.

Figure 6 - Regression discontinuity at the end of DST in models without covariates

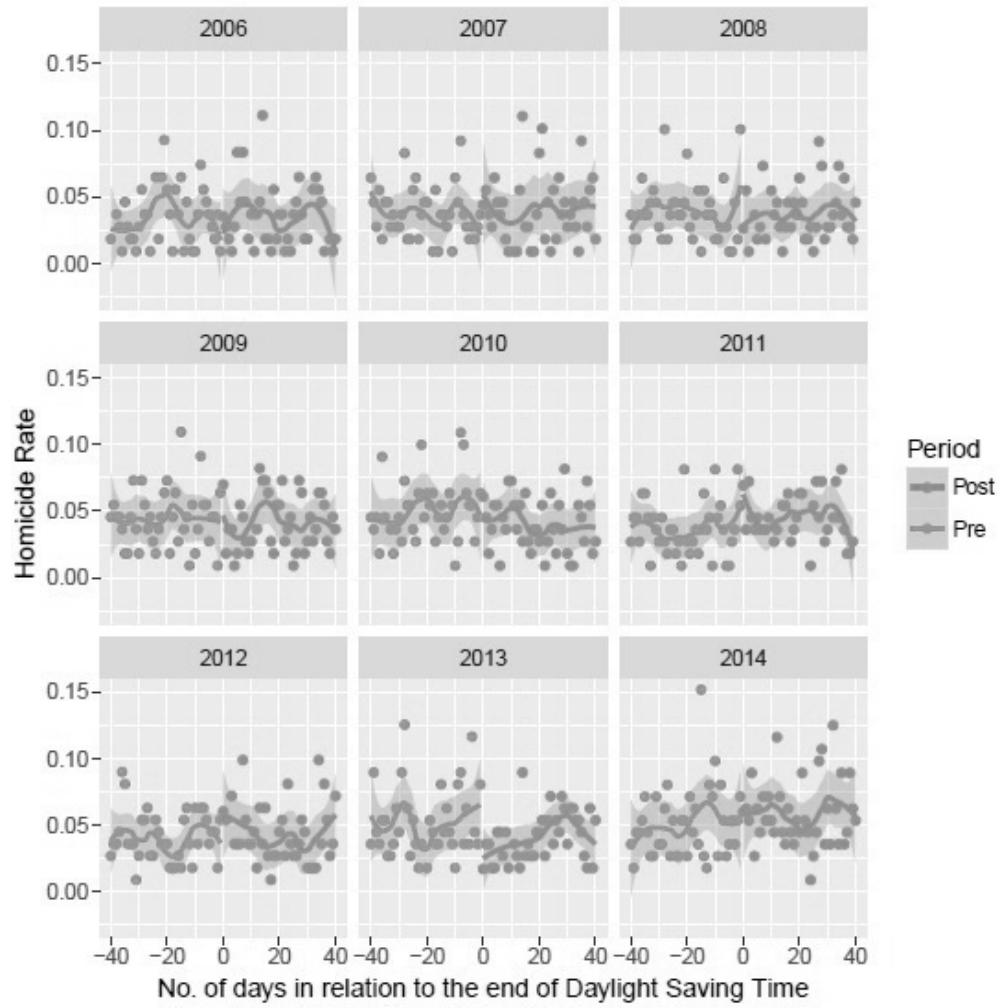

Source: Elaborated by the author; SIM ([2018]); FEE ([2018]).. 
There is absence again of statistical significance in all the years of the series. Virtually all effects estimated for $\tau$ do not have any statistical evidence indicating discontinuity, with the exception of the year 2013. This year we saw that we had the negative effect of $\tau=0.0374$ for the model with covariates and $\tau=0.0346$ for the simplest model. What draws attention, again, to this result is that the direction of the effect is the opposite of what is expected. The intervention of leaving the DST implies less light during the day which would lead to an increase in the homicide rate, which was not the case. In addition, it should be considered that, in this year there was an abrupt increase in wind speed just at the exit of the DST. Therefore, this effect of reducing crime may be confused with increasing wind speed, since we have seen that these two variables can be related according to the already discussed results.

With regard, the effect of the covariates on the end of DST, only Temperature in 2012 ( $\beta=0.0021$ e Sig. $=0.0149)$ and Wind Speed in $2006(\beta=0.0096$ e Sig. $=0.0313$ ) showed significant results. Again, there is evidence that as temperatures rise, criminal rates increase as well. On the other hand, the Wind Speed result indicates that, in 2006, as there is more wind, higher homicide rates occur.

The effects of the weekdays at the exit of DST and their indications are analogous to those discussed in Section 4.2. It is possible to note that the "weekend" effect remains present since Saturday's $\beta$ 's are not significant and weekdays have significant negative effect for most of the values.

In general, these results of the end of DST only confirm the main results found for the start period. That is, without evidence that DST has an influence on crime. In terms of model results with covariables, it was observed that in both cases, weekend effects are strong and there is evidence of a positive relationship between temperature and homicide in some years (especially in start models for DST).

\section{Robustness Checks}

The results found do not indicate a significant effect in many of the cases of DST in homicide rates. This section is devoted to evaluating the method used under different estimation techniques.

\subsection{Estimation with Demean Approach}

The first robustness check is given by the nature of the variable $Y$ to be estimated in the discontinuity regression. The demean method used in Smith (2016) and Toro et al. (2016) seeks to remove the possible confounding effects of the method by correcting the dependent variable by making $Y$ the logarithm of the value adjusted by the mean of homicides occurred on that day of the week, in that speci- 
fic region and in that specific year. ${ }^{11}$ In this case, there would be no need to include weekday covariates nor the need to estimate separate models per year, but it would make the use of climatic covariates unfeasible. In this sense, the model to be estimated follows the Equation 8. In both results, we again verified the non-significance of the DST effect for both start and end models. This result is in line with the findings of this study, indicating that there is no effect of DST on homicides in RS.

\subsection{Sex Difference}

The possible sudden change in homicide rates that the DST might cause could have could affect differently depending on the sex of the victim. ${ }^{12}$ Although the sex differences in crime has already been studied in the literature (ROWE et al., 1995; FOX; FRIDEL, 2017), it is unheard in the literature the difference in the effects related to the implementation DST policy. It was conducted nonparametric differences-in-differences (diff-in-diff) according to Equation 9 for the demean approbeginningthe beggining and the end of DST period.

$$
H R_{d}=\beta_{0}+\tau_{T} I\left(T_{d \mathrm{~s}} \geq 0\right)+\tau_{s} I\left(S_{\mathrm{s}}\right)+\tau_{E} I\left(T_{d \mathrm{~s}} \geq 0\right) \times I\left(S_{\mathrm{s}}\right)+g\left(T_{d \mathrm{~s}}\right)+\varepsilon_{d \mathrm{~s}}
$$

In this model, assuming similar tendencies close to the change in the DST for men and women, it captures this sex effect through the $\tau_{E}$ which evaluates the difference of sex in the differences of periods. For more details of the diff-in-diff approach we recommend Angrist and Pischke (2013).

Both models were estimate and the results point the absence of differences in sex for either entry or end of DST. For the initial model $\tau_{E}$ was estimated in -0.02 with significance of 0.77 and, for the model of the end of DST, the same parameter was estimated in -0.09 with significance of 0.21 . Therefore, the absence of significance evaluated that there is no evidence that the DST affects differently men and women in the dataset.

\subsection{Bandwidth Choice}

One of the components of nonparametric estimation is the choice of the smoothing parameter (or bandwidth) in the local regression. Calonico et al. (2014) discuss robust ways of estimating discontinuity regressions, as well as proposing

\footnotetext{
11 This method adjusts the number of homicides on each day of the week in each region in each year by the average number of homicides occurred on that day of the week, in that region and in that specific year. For example, the dependent variable for, to say, the Monday following the DST transition in the state of RS in the year of 2008 is the logarithm of the number of homicides on that Monday in RS divided by the average number of homicides occurred during all the Mondays of 2008 in RS.

We thank the reviewer for pointing out the possibility of this robustness check.
} 
alternative bandwidths. Using the authors' approach, we estimated the start and end models of DST. ${ }^{13}$

Table 5 shows the results of the effect of DST $(\tau)$ on start and end models. Although there was a larger set of significance, the changes were not very substantial since, again, in virtually all models and years there was no significant effect of $\tau$. The biggest highlights of the entry are in 2006, 2010 and 2013 for models with covariates. Regarding the end of DST, this bandwidth pointed out some interesting significance as an increase in the homicide rate in 2007 in both models and a reduction in the rate in 2013 in line with the results previously presented.

Table 5 - Results of DST using alternative bandwidth

\begin{tabular}{l|ccc|ccc}
\hline \multirow{2}{*}{ Year } & Effects $(\tau)$ & Significance & $\begin{array}{c}\text { Does it include } \\
\text { covariates? }\end{array}$ & Effects $(\tau)$ & Significance & $\begin{array}{c}\text { Does it include } \\
\text { covariates? }\end{array}$ \\
\cline { 2 - 6 } & & Entry & & & End & \\
\hline 2006 & 0.0404 & 0.0001 & Yes & 0.0690 & 0.0097 & Yes \\
2006 & 0.0242 & 0.3121 & No & 0.0192 & 0.2072 & No \\
2007 & 0.0088 & 0.5503 & Yes & 0.0545 & 0.0000 & Yes \\
2007 & 0.0287 & 0.0764 & No & 0.0332 & 0.0006 & No \\
2008 & 0.0125 & 0.0563 & Yes & -0.1228 & 0.0000 & Yes \\
2008 & 0.0254 & 0.3210 & No & -0.0463 & 0.2834 & No \\
2009 & -0.0112 & 0.2031 & Yes & 0.0134 & 0.3403 & Yes \\
2009 & 0.0062 & 0.8225 & No & 0.0133 & 0.6456 & No \\
2010 & -0.0145 & 0.0273 & Yes & -0.0234 & 0.0001 & Yes \\
2010 & 0.0012 & 0.9505 & No & -0.0131 & 0.3561 & No \\
2011 & -0.0033 & 0.6611 & Yes & 0.0029 & 0.6365 & Yes \\
2011 & -0.0017 & 0.9028 & No & -0.0101 & 0.5902 & No \\
2012 & 0.0044 & 0.5971 & Yes & -0.0040 & 0.6762 & Yes \\
2012 & -0.0046 & 0.7194 & No & 0.0255 & 0.0867 & No \\
2013 & 0.0187 & 0.0004 & Yes & -0.0264 & 0.0104 & Yes \\
2013 & 0.0130 & 0.3171 & No & -0.0404 & 0.0507 & No \\
2014 & 0.0172 & 0.0730 & Yes & -0.0059 & 0.4047 & Yes \\
2014 & -0.0042 & 0.8693 & No & 0.0057 & 0.6762 & No \\
\hline
\end{tabular}

Source: Elaborated by the author.

13 We highlight that, for this, it was necessary to make use of the rdrobust package presented and described in Calonico et al. (2015) in software R (R CORE TEAM, 2016), where the optimal bandwidth used in this section minimizes the mean squared error. In Section 4, the estimation was performed using Generalized Additives Models and the package gam (HASTIE, 2017) was used because with it the marginal effects of covariates could be analyzed. 


\subsection{Most affected Hours by the DST}

One of the main hypotheses raised in Doleac and Sanders (2005) and Toro et al. (2016) is that DST has a more pronounced effect in the hours closer to the transition between day and night, that is, in the hours closer to sunset. In these works, there is evidence that the effects are greater at times close to sunset. In this sense, it is also of interest to verify if this hypothesis holds for the case of RS. ${ }^{14}$

We investigated the results of the entry and exit, respectively, of the DST by the demean method making use of only the cases that happened near the sunset. In the period of entry, again, we see no significant effect on the transition. However, in the case of exit we observed weak but non-significant (Sig. $=0.0668)$ evidence that there was an increase in homicide rate, which is in the sense of the main hypothesis of this article that less light indicates an increase in delinquency practice.

\subsection{Analysis at All Death Occurrence Location}

In Section 3.1, it is described that the models are estimated only in cases where the death occurred outside hospitals and other health facilities implying a loss of $27.54 \%$ of cases. Such treatment is due to the fact that it is possible that there is a reallocation of the day between the criminal occurrence and the time of death, something that is undesirable in this article considering the character of daily analysis of the local effect of DST. However, it is possible to assume that this loss of sample will affect the estimated results of this paper.

In this sense, this Section 5.5 is dedicated to presenting the results taking into account the whole universe of homicides of the base of the SIM independent of the place of criminal occurrence. It is noteworthy that between 2006 and 2014 this entire base results in 19,318 cases.

Table 6 shows the local effects of DST taking into account all cases of the database regardless of the place of occurrence. For the start models in the DST, again we did not identify any substantial changes in relation to the absence of significance of the Table 4.1, except that with this approach the year of 2010 (with covariates) showed a significant reduction and not in the year of 2007 (without covariates) as seen previously. Regarding the end of the DST, the consonance with the results obtained is even greater, because, again, only the year of 2013 had a significant reduction in the models in the same way as was discussed in Section 4.3.

14 The time considered as close to sunset is between $17 \mathrm{pm}$ and $21 \mathrm{pm}$. 
Table 6 - Local effects of the DST for all years and models: all occurrence locations

\begin{tabular}{|c|c|c|c|c|c|c|}
\hline \multirow{2}{*}{ Year } & Effects $(\tau)$ & Significance & $\begin{array}{l}\text { Does it include } \\
\text { covariates? }\end{array}$ & Effects $(\tau)$ & Significance & $\begin{array}{l}\text { Does it include } \\
\text { covariates? }\end{array}$ \\
\hline & \multicolumn{3}{|c|}{ Entry } & \multicolumn{3}{|c|}{ End } \\
\hline 2006 & 0.0041 & 0.6962 & Yes & 0.0007 & 0.9465 & Sim \\
\hline 2006 & 0.0053 & 0.6621 & No & 0.0071 & 0.5742 & Não \\
\hline 2007 & 0.0036 & 0.7122 & Yes & 0.0120 & 0.2709 & Sim \\
\hline 2007 & 0.0061 & 0.5361 & No & 0.0121 & 0.3227 & Não \\
\hline 2008 & -0.0034 & 0.7700 & Yes & -0.0192 & 0.0901 & Yes \\
\hline 2008 & 0.0020 & 0.8825 & No & -0.0137 & 0.2676 & No \\
\hline 2009 & -0.0070 & 0.4778 & Yes & 0.0003 & 0.9765 & Yes \\
\hline 2009 & -0.0026 & 0.7923 & No & 0.0053 & 0.6663 & No \\
\hline 2010 & -0.0221 & 0.0134 & Yes & -0.0176 & 0.2050 & Yes \\
\hline 2010 & -0.0147 & 0.1198 & No & -0.0176 & 0.1851 & No \\
\hline 2011 & 0.0016 & 0.8427 & Yes & -0.0010 & 0.9155 & Yes \\
\hline 2011 & 0.0034 & 0.6857 & No & 0.0011 & 0.9102 & No \\
\hline 2012 & -0.0014 & 0.8846 & Yes & -0.0097 & 0.2710 & Yes \\
\hline 2012 & -0.0007 & 0.9471 & No & -0.0068 & 0.4835 & No \\
\hline 2013 & -0.0029 & 0.7828 & Yes & -0.0406 & 0.0008 & Yes \\
\hline 2013 & -0.0020 & 0.8539 & No & -0.0341 & 0.0052 & No \\
\hline 2014 & 0.0018 & 0.8759 & Yes & 0.0153 & 0.2643 & Yes \\
\hline 2014 & 0.0072 & 0.5599 & No & 0.0119 & 0.3832 & No \\
\hline
\end{tabular}

Source: Elaborated by the author.

\section{Final Considerations}

The purpose of this article was to study the effect of the entry and exit of DST on homicides in the Brazilian state of Rio Grande do Sul. The idea was to verify if the increase of the luminosity, caused by the entrance in the DST, has deterrent effect criminal. There is strong evidence in this sense that most homicides occur under darkness, peaking at 10 o'clock persisting until early morning hours, indicating that aggressors prefer to act during the nighttime period.

Using the Brazilian Mortality Information System (SIM) homicide data, which has date and time information of the event, this study evaluated the effect of a possible discontinuity in the criminal activity both at the beginning and end of DST in the period 2006-2014. Under the hypothesis of lightening deterrence, it was expected that at the beginning of DST, there would be a drop in the homicide rate and, at the end of it, an increase.

The approach used RDD in which non-parametric models are estimated for the pre and post-intervention period and assess whether the local effect of transition from DST intervention is significant. In addition, the idiosyncrasies of the data are contemplated as the inclusion of fixed effect of day of the week, climatological covariables and separate estimations per year of each model. 
The results showed that DST, in general, has no effect on the homicide rate. It was evidenced that in almost all the years of the historical series the effect of the DST was null with regard to the change in the level of the homicide rate. Besides, in some cases the results that were significant pointed in the opposite-to-expected sense, such as in 2007 that there was an increase in homicides when DST was started and in 2013 that there was a reduction in homicides when the DST ended. ${ }^{15}$ In this sense, although there is strong evidence that there is a luminosity effect on criminal activity when we analyze the hours of the day the homicides occur, it is not captured by the model when we analyze the effect of DST alone. One of the hypotheses to be considered for this lack of effect is that, although the change in DST time is sudden, the presence of "more" light during the day is actually gradual and in interstices, which mitigates the sharp effect of the discontinuous intervention. It is important to note that many variables affect delinquency behavior.

History of behavioral problems in childhood (MURRAY et al., 2015), use of alcohol (MCBRIDE et al., 1991; DEARDEN; PAYNE, 2009) and social inequality (KELLY, 2000; FAJNZYLBER et al., 2002), for example, are factors that can influence criminal activity. Specifically, it is of interest to carry out future studies regarding the relationship between alcohol consumption and homicides for RS. In the analyzes presented here, we find that weekday plays a crucial role in criminal rates, where the weekend is when more crimes happen. In addition, strong evidence of a positive correlation between temperature and homicides was estimated.

The results estimated in this article were robust to variations of model specifications. Alternative approaches were tested such as the use of the demean method for estimation of RDD, alternative smoothing parameters, estimation for only those cases that occurred at hours more affected by DST and not excluding occurrences in hospitals and health facilities. In almost all situations, this intervention did not have a good explanatory power in the change of homicide rates.

This article advances considerably in the literature on the economics of crime because of its pioneering character of local evaluation of the DST effect on RS crimes. Up to the present time, no work is known that addressed this topic in the state. The discussion of the effects of DST is extremely relevant because it is a public policy that affects all the inhabitants of a certain place and studies that evaluate its true impact on the most different aspects are important to subsidize the public authorities to think/rethink this measure and its consequences in society. In 2017, the Brazilian federal government studied the possibility of excluding DST from the national calendar claiming that its main purpose of energy saving is not achieved, considering also to carry out popular consultation to evaluate its revocation. In this sense, studies like this one carried out are justified.

$15 \quad$ Possible confounding effect with wind speed. 


\section{References}

ANDRESEN, M. A. Environmental criminology: evolution, theory, and practice. Abingdon: Routledge, 2014.

ANDRESEN, M. A.; MALLESON, N. Intra-week spatial-temporal patterns of crime. Crime Science, v. 4, n. 1, p. 12, 2015.

ANGRIST, J. D.; PISCHKE, J. S. Mostly harmless econometrics: an empiricist's companion. Princeton: Princeton University Press, 2013.

ARIES, M. B. C.; GUY, R. N. Effect of daylight saving time on lighting energy use: a literature review. Energy Policy, v. 36, n. 6, p. 1858-1866, 2008.

ARVATE, P.; FALSETE, F. O.; RIBEIRO, F. G.; SOUZA, A. P. Lighting and violent crimes: evaluating the effect of an electrification policy in rural Brazil on violent crime reduction. Textos para Discussão FGV, n. 408, 2015.

BECKER, G. Crime and punishment: an economic approach. Journal of Political Economy, v. 76, n. 2, p. 169-217, 1968.

BRITTO, M. C. Análise dos homicídios ocorridos em Juiz de Fora entre os anos de 1980 a 2012 e sua relação com as condições climáticas. Revista Brasileira de Climatologia, v. 13, 2014.

CALONICO, S.; CATTANEO, M. D.; TITIUNIK, R. Robust nonparametric confidence intervals for regression-discontinuity designs. Econometrica, v. 82, n. 6, p. 2295-2326, 2014.

CALONICO, S.; CATTANEO, M. D.; TITIUNIK, R. Rdrobust: an R package for robust nonparametric inference in regression-discontinuity designs. $R$ Journal, v. 7, n. 1, p. 38-51, 2015.

CECCATO, V. Homicide in São Paulo, Brazil: assessingspatial-temporal and weather variations. Journal of Environmental Psychology, v.25, n. 3, p. 307-321, 2005.

CECCATO, V.; UITTENBOGAARD, A. C. Space-timeerseysid oerseye in stockholm, sweden. In: SPATIAL STATISTICS-MAPPING GLOBAL CHANGE, 1., 2011, The Netherlands. Proceedings [...]. The Netherlands: Elsevier, 2011. p. 1-8.

CECCATO, V.; UITTENBOGAARD, A. C. Space-time dynamics of crime in transport nodes. Annals of the Association of American Geographers, v. 104, n. 1, p. 131-150, 2014.

CLEVELAND, W. S.; DEVLIN, S. J. Locally weighted regression: an approach to regression analysis by local fitting. Journal of the American Statistical Association, v. 83, n. 403, p. 596610, 1988.

COHN, E. G.; ROTTON, J. Weather, seasonal trends aerseyside crimes in minneapolis, 19871988. A moderator-variable time-series analysis of routine activities. Journal of Environmental Psychology, v. 20, n. 3, p. 257-272, 2000. 
DEARDEN, J.; PAYNE, J. Alcohol and homicide in Australia. Trends 8 Issues in Crime and Criminal Justice, n. 372, 2009.

DEE, T.; WYCKOFF, J. Incentives, selection and teacher performance: evidence from IMPACT. NBER Working Paper, n. 19529, 2013.

DE SOUZA, M. F. M.; MACINKO, J.; ALENCAR, A. P.; MORAIS NETO, O. L. Reductions in firearm-related mortality and hospitalizations in Brazil after gun control. Heath Affairs, v. 26, n. 2, 2007.

DOLEAC, J. L.; SANDERS, N. J. Under the cover of darkness: how ambient light influences criminal activity. Review of Economics and Statistics, v. 97, n. 5, p. 1093-1103, 2005.

FAJNZYLBER, P.; LEDERMAN, D.; LOAYZA, N. Inequality and violent crime.

The Journal of Law and Economics, v. 45, n. 1, p. 1-39, 2002.

FARRELL, G.; PEASE, P. Crim seasonality: domestic disputes and residential burglary in Merseyside 1988-90. The British Journal ofCriminology, v. 34, n. 4, p. 487-498, 1994.

FUNDAÇÃO DE ECONOMIA E ESTATÍSTICA (FEE). Available at: https://arquivofee.rs.gov. br/. Access: Apr. 10, 2021.

FIELD, S. The effect of temperature on crime. The British Journal of Criminology, v. 32, n. 3 , p. 340-351, 1992.

FOX, J. A.; FRIDEL, E. E. Gender differences in patterns and trends in US homicide, 19762015. Violence and Gender, v. 4, n. 2, p. 37-43, 2017.

GAMBLE, J. L.; HESS, J. J. Temperature and violent crime in Dallas, Texas: relationships and implications of climate change. Western Journal of Emergency Medicine, v. 13, n. 3, p. 239, 2012.

HASTIE, T. GAM: generalized additive models. R package version 1.14- 4. [S. 1.]: Stanford University, 2017. Available at: https://CRAN.R-project.org/package=gam. Access: Jan. 19, 2021.

HORROCKS, J.; MENCLOVA, A. K. The effects of weather on crime. New Zealand Economic Papers, v. 45, n. 3, p. 231-254, 2011.

KELLOGG, R.; WOLFF, H. Daylight time and energy: evidence from an Australian experiment. Journal of Environmental Economics and Management, v. 56, n. 3, p. 207-220, 2008.

KELLY, M. Inequality and crime. The Review of Economics and Statistics, v. 82, n. 4, p. 530-539, 2000 .

KOTCHEN, M. J.; GRANT, L. E. Does daylight saving time save energy? Evidence from a natural experiment in Indiana. The Review of Economics and Statistics, v. 93, n. 4, p. 1172-1185, 2011.

KOUNTOURIS, Y.; REMONDOU, K. About time: daylight saving time transition and individual well-being. Economics Letters, v. 122, n. 1, p. 100-103, 2014. 
LANDAU, S. F.; FRIDMAN, D. The seasonality of violent crime: the case of robbery and homicide in Israel. Journal of Research in Crime and Delinquency, v. 30, n. 2, p. 163-191, 1993.

LOEFFLER, C. E.; GRUNWALD, B. Processed as an adult: a regression discontinuity estimate of the crime effects of charging nontransfer juveniles as adults. Journal of Research in Crime and Delinquency, v. 52, n. 6, p. 890-922, 2015.

MCBRIDE, A. A.; JOE, G. W.; SIMPSON, D. D. Prediction of long-term alcohol use, druguse, and criminality among inhalant users. Hispanic Journal of Behavioral Sciences, v. 13, n. 3, p. 315-323, 1991.

MENEZES FILHO, N. et al. Avaliação econômica de projetos sociais. São Paulo: Dinâmica: Fundação Itaú, 2012.

MICHEL, S. J.; WANG, H.; SELVARAJAH, S.; CANNER, J. K.; MURRILL, M.; CHI, A.; EFRON, D. T.; SCHNEIDER, E. B. Investigating the relationship between weather and violence in Baltimore, Maryland, USA. Injury, v. 47, n. 1, p. 272-276, 2016.

MURRAY, J. et al. Childhood behaviour problems predict crime and violence in late adolescence: Brazilian and British birth cohort studies. Social Psychiatry and Psychiatric Epidemiology, v. 50, n. 4, p. 579-589, 2015.

NEWTON, A.; HIRSCHFIELD, A. Measuring violence in and around licensed premises: the need for a better evidence base. Crime Prevention and Community Safety, v. 11, n. 3, p. 171$188,2009$.

R CORE TEAM. R: a language and environment for statistical computing. Vienna: R Foundation for Statistical Computing, 2016. [2018]. Available at: https://www.R-project.org/. Access: Jan. 19, 2021.

RANSON, M. Crime, weather, and climate change. Journal of Environmental Economics and Management, v. 67, n. 3, p. 274-302, 2014.

ROTTON, J.; COHN, E. G. Global warming and us crime rates: an application of routine activity theory. Environment and Behavior, v. 35, n. 6, p. 802-825, 2003.

ROWE, D. C.; VAZSONYI, A. T.; FLANNERY, D. J. Sex differences in crime: do means and within-sex variation have similar causes? Journal of Research in Crime and Delinquency, v. 32, n. 1, p. 84-100, 1995.

SALVI, S. Does increased lighting reduce crime? Studying the impact of the summer night lights program on crime in Los Angeles. Massachusetts: Amherst College, 2011.

SILVEIRA, C.; VIEIRA, R. O. Relação entre o comportamento anual da temperatura média mensal do ar e o comportamento anual da criminalidade da cidade de Pelotas-RS. In: CONGRESSO BRASILEIRO DE METEOROLOGIA, 11., 2001. Anais [...]. Rio de Janeiro, 2001.

SIM. Sistema de Informações de Mortalidade. Available at: http://www2.datasus.gov.br/DATASUS/index.php?area=060701. [2018]. Access: Apr. 10, 2021. 
SMITH, A. C. Spring forward at your own risk: daylight saving time and fatal vehicle crashes. American Economic Journal: Applied Economics, v. 8, n. 2, p. 65-91, 2016.

THISTLEWAITE, D.; CAMPBELL, D. Regression-discontinuity analysis: an alternative to the ex post facto experiment. Journal of Educational Psychology, v. 51, n. 6, p. 309-317, 1960.

TOMPSON, L. A.; BOWERS, K. J. Testing time-sensitive influences of weather on street robbery. Crime Science, v. 4, n. 8, 2015.

TORO, W.; TIGRE, R.; SAMPAIO, B. Daylight saving time and incidence of myocardial infarction: evidence from a regression discontinuitydesign. Economics Letters, v. 136, p. 1-4, 2015.

TORO, W.; TIGRE, R.; SAMPAIO, B. Ambient light and homicides. 2016. Available at: https:// www.researchgate.net/publication/303722245_Ambient_Light_and_Homicides. Access: April, 4, 2021.

WOLFF, H.; MAKINO, M. Extending Becker's time allocation theory to model continuous time blocks: evidence from daylight saving time. IZA Discussion Paper, n. 6787, 2012.

\section{Autor correspondente:}

Renan Xavier Cortes

Recebido em: 01/02/2018.

E-mail: renanxcortes@gmail.com

Aceito em: 22/08/2018.

\section{(cc) BY}

Este é um artigo de acesso aberto distribuído sob os termos da Creative Commons Attribution CC-BY 4.0, que permite uso irrestrito, distribuição e reprodução em qualquer meio, desde que o trabalho original seja devidamente citado. 